\title{
Dynamic Water Effect on the High Temperature Stability of Asphalt
}

\author{
Mixture \\ Hou Minghao ${ }^{1, \mathrm{a}}$, Tan Yiqiu, ${ }^{1, \mathrm{~b}}, \mathrm{Hu} \mathrm{Bin}^{2, \mathrm{c}}$ \\ ${ }^{1}$ Candidate of $\mathrm{PhD}$, School of Traffic Science and Engineering, Harbin Institute of Technology, \\ No.73 Huanghe Road Nangang District, Harbin, Hei Longjiang, China, 150090, \\ ${ }^{1}$ Professor, School of Traffic Science and Engineering, Harbin Institute of Technology, No.73 \\ Huanghe Road Nangang District, Harbin, Hei Longjiang, China, 150090, \\ ${ }^{2}$ Candidate of PhD, Institute of Road Engineering, South China University of Technology, No.381 \\ Wushan Road Tianhe District, Guangzhou, Guangdong, China, 510640, \\ aemail:houminghao@hit.edu.cn bemail: yiqiutan@163.com `email:hbhit@163.com
}

Keyword: dynamic water, asphalt mixture, high temperture, simulation device

\begin{abstract}
This paper introduces dynamic water effect into the test, develops a laboratory test device for simulating the dynamic water effect on asphalt pavement, and puts forward a test method of dynamic water effect working together with load, water and temperature. Based on this method, the high temperature stability of seven kinds of asphalt mixtures with the factors of asphalt grade, gradation and air voids are studied. The research shows that the effect of dynamic water can take adverse effect for the high temperature stability of asphalt mixture. The effect degree is different under different factors. It is the most disadvantaged when the air voids of the mixture is near $10 \%$, the skeleton structure gradation of mixture is better than the suspended structure at the most disadvantage air voids, and the mixture made of high viscosity asphalt is more affected when the temperature is higher.
\end{abstract}

\section{Introduction}

Along with the increasing traffic volume, traveling speed and axle loads, serious premature failures occurred on many asphalt pavements soon after opening to the traffic, such as flooding oil, loose inside, frost boiling, settlement and bottom stripping [1]. The premature failures of asphalt pavements are one of the main problems of pavements' maintenance. Existing researches show that the premature failures are related to the water influence on asphalt pavement, the pressure of the dynamic water caused by high speed driving on the pavements is the main factor for premature failures [2]. In recent years, the research about water effect on asphalt pavement mainly concentrated on the cause and mechanism of water damage [3]. There are many test methods and standards for evaluation water damage of asphalt mixture, and also corresponding technical measures about control of water damage happened [4]. However, water-related damage of asphalt pavement continuously emerging in the practice engineering, that is because currently research for the dynamic water effect on the road performance of asphalt mixture is paid inadequate attention.

Most regions in our country, the high temperature season is also a rainy season, asphalt pavement under the effect of the water and high temperature. Because of the dynamic load of traffic and temperature expansion and contraction repeated affect, the water which enter the asphalt pavement voids continuously generate hydrodynamic pressure or the vacuum cycle, water gradually infiltrated into the interface of asphalt and aggregate, then the asphalt will be emulsified, the 
strength of asphalt mixture will be declined [5]. Because of the dynamic water, asphalt membrane gradually stripped from the aggregate surface, the aggregate loss of bond strength between the asphalt mixtures arising out beads and loose, and then asphalt pavement appears pit and pushing deformation damage [6]. That is seriously reducing the use of pavement performance, endangering the traffic safety, shortening the life of asphalt pavement, and causing enormous economic losses. Therefore, the study of dynamic water effect of asphalt mixture high temperature stability is very necessary.

\section{Mixture specimens preparation}

This study uses three types gradation which are SMA-16, AC-16 and SAC-16. In order to research on the different asphalt grade, different gradation and different air voids of asphalt mixture, this paper select 90 \#, 110 \#, 130 \# three type asphalt, three kinds of gradations which are AC-16, SAC-16 and SMA-16 and three kinds of air voids that are $6 \%, 10 \%, 14 \%$ to prepare seven kinds of asphalt mixtures, their specific composition are shown in Table 1. Existing research shows that when the air voids of mixture is between $8 \% \sim 12 \%$, the mixture will be more impacted by water. Engineering site investigation also found that the air voids of the roads which appear water damage are mostly in this context. Therefore, $10 \%$ air voids is selected as the main air voids of the asphalt mixture in this paper. The Mixture specimens sizes used in the study are $100 \mathrm{~mm} \times 63.5 \mathrm{~mm}$, the specimens are rotary compaction molding. The molding method can accurately control the shape of the specimen height, and thus better control the specimen's air voids.

Table 1. Basic composition of the asphalt mixtures

\begin{tabular}{cccc}
\hline Mixture type & Asphalt grade & Gradation & Air voids (\%) \\
\hline A & $90 \#$ & AC-16 median & 10 \\
B & $110 \#$ & AC-16 median & 10 \\
C & $130 \#$ & AC-16 median & 10 \\
D & $110 \#$ & SAC-16 median & 10 \\
E & $110 \#$ & SMC-16 median & 10 \\
F & $110 \#$ & AC-16 median & 6 \\
G & $110 \#$ & AC-16 median & 14 \\
\hline
\end{tabular}

\section{Dynamic water effect test simulation}

Dynamic water effect test device development The study designs a laboratory teat device simulating the dynamic water effect on asphalt mixture, the schematic diagram and actual picture of the device are shown in Fig. 1.

The main body of the device is scouring barrel, its wall thickness is $10 \mathrm{~mm}$. It is made of transparent plexiglass material, the mixture specimen can be put in it, there is support drums and clasp which will make the specimen at the fixed location. To ensure that device can withstand the test required pressure, the lateral wall of the barrel body is hooped with sheet iron, the cover and barrel are reinforced with steel plate and screw clamp. One said wall of the Barrel has two water districts separated by specimen which connected with a catheter; the other side has two valves, the lower valve is used for water injection and water drainage, the upper valve connect the external hydraulic pressure gage, which can measure the Real-time water pressure conveniently. In order to ensure the device is sealed, the contact area of the piston rod with the barrelhead and the barrelhead with barrel body are treated with the sealing tape and sealing ring. In addition the lateral edge of the mixture specimen in the scour barrel should be wrapped with thin rubber parcels, to strengthen its sealing relationship with the inner wall of device. Do the best to minimize the water stream from the gap over which causes the erosion effect weakening. During the test, the upper rod and lower base fixed at the upper and lower pressure head of MTS testing machine. Lubricating oil is put on the piston rod to ensure it well contacting with the barrelhead. 
In the test, the MTS pressure head moves downward, water in the A district is pressed down into the air voids of specimen, some water through the specimen connectivity void into the B district, that process is simulating the water of the road surface is pressed into the road voids under the wheel load pressure. Similarly, when the MTS pressure head moves up rapidly, the water in the B district will make the opposite path enter into the A district, this situation is simulating the void water pumping effect when the wheels leave the road. MTS pressure head moves up and down repeatedly, so that the water in the device is repeatedly washing the specimen, which simulates the water at the wheel loads on the asphalt pavement washed repeatedly the air voids. The piston does not contact the specimen during the test.
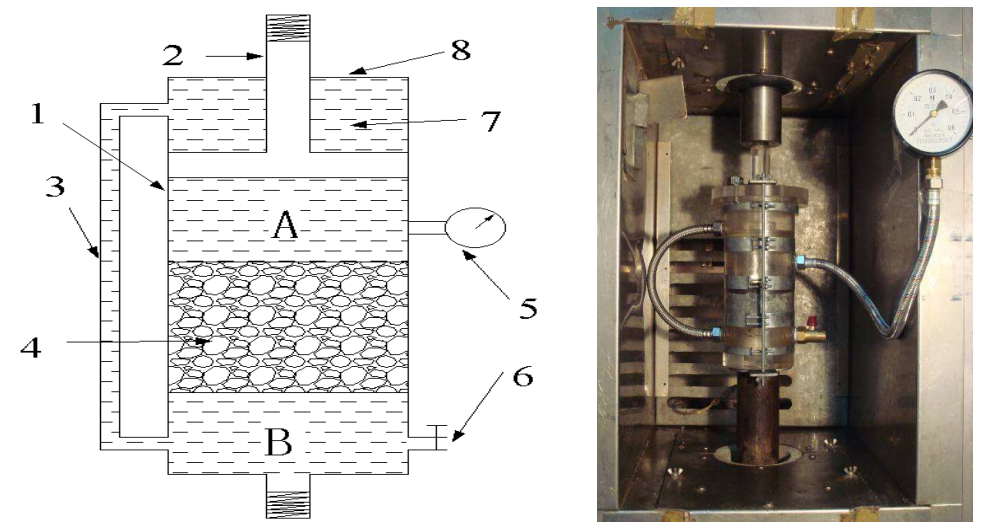

1 - Scour barrel 2 - Pistons

3 - Catheter 4 - Specimen

5 - Pressure gauge 6 - Valve

7 - Water 8 - Barrelhead

Fig. 1. The dynamic water test device

Dynamic water effect test conditions:For accurate simulation of dynamic water scouring effect on the mixture specimens, and quantitative analysis for it, the test conditions should be determined firstly. Selection of experimental conditions is considered with the simulation of the actual situation, and also with the difficult degree for the test implementation. According to the original selection of test condition scope for the scouring frequency, scouring pressure, scouring time and scouring temperature, the $15{ }^{\circ} \mathrm{C}$ splitting intensity ratio of the specimens are measured which are affected by the dynamic water test under different conditions, the test conditions are determined. The test temperature is $45^{\circ} \mathrm{C}$, the scouring pressure is $0.4 \mathrm{Mpa}$ and the scouring time is 15 minutes. Based on that condition, the dynamic water test is conducted with the seven kinds of asphalt mixtures.

Influence of dynamic water on high temperature stability

Table 2. Creep rate change for mixtures before and after dynamic water effect

\begin{tabular}{cccc}
\hline \multirow{2}{*}{ Mixture type } & \multicolumn{2}{c}{ Creep rate $\left(10^{-6} / \mathrm{s} / \mathrm{Mpa}\right)$} & \\
\cline { 2 - 3 } & $\begin{array}{c}\text { Before dynamic } \\
\text { water effect }\end{array}$ & $\begin{array}{r}\text { After dynamic water } \\
\text { effect }\end{array}$ & Change rate $(\%)$ \\
\hline A & 253.7 & 646.4 & 154.8 \\
B & 289.1 & 670.9 & 132.1 \\
C & 2062.0 & 3447.6 & 67.2 \\
D & 692.8 & 1178.3 & 70.1 \\
E & 561.3 & 878.8 & 56.6 \\
F & 289.1 & 670.9 & 132.1 \\
G & 2037.5 & 2160.2 & 6.0 \\
\hline
\end{tabular}

Connected with reality, this study uses splitting creep test to evaluate the high temperature stability of asphalt mixture. Creep rate is selected as evaluation index in order to see the high-temperature resistance to deformation capacity of mixture more directly. The test temperature 
is $45^{\circ} \mathrm{C}$, load splitting tensile stress is $0.025 \mathrm{Mpa}$. The test is separately carried on the specimens before and after the dynamic water effect of the seven kinds of asphalt mixtures. The test results are shown in Table 2.

Asphalt gradeThe physical properties of asphalt have impacted on the resistance to rutting performance of mixture. At a certain temperature and loading rate, the greater the viscosity of asphalt is, the greater the viscous resistance is, the stronger the anti-shear deformation ability is, and the resistance to rutting performance of asphalt mixture is better. Asphalt viscosity changes with temperature, the lower the temperature sensitivity is, then the formation of the corresponding asphalt mixtures have better high temperature stability, this relationship has been confirmed by the rapid loading test. Asphalt Binder provided the cohesive force is closely related to the nature performance of asphalt mixture, the asphalt content and the interaction between the asphalt and aggregate. The cohesive force of asphalt mixture is relevant to the cohesive force of asphalt at high temperature conditions.

To study the degree of the high temperature stability of mixtures with different asphalt grades under dynamic water effect, $\mathrm{A}, \mathrm{B}$ and $\mathrm{C}$ are selected in this test, the experimental results are shown in Fig. 2-Fig.4. The real line in the diagram is representation for the creep curve of the specimens before dynamic water effect, and the broken line is representation for the creep curve of the specimens after dynamic water effect.

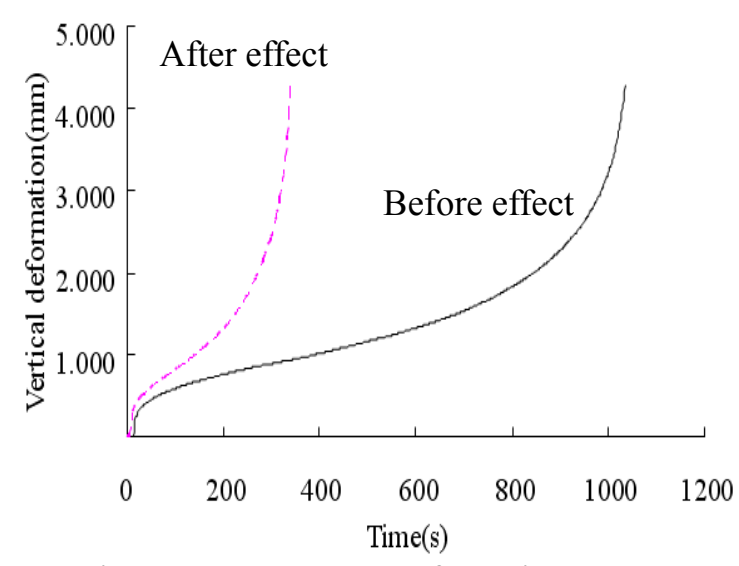

Fig. 2. Creep curve of A mixture

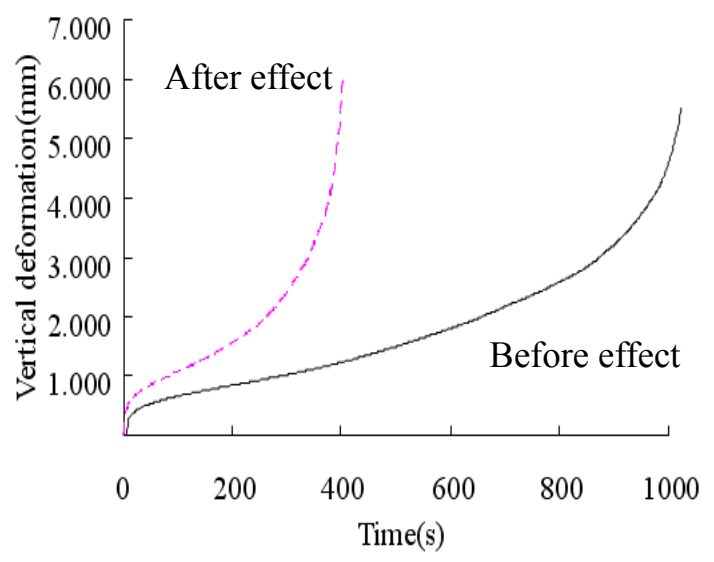

Fig.3. Creep curve of B mixture

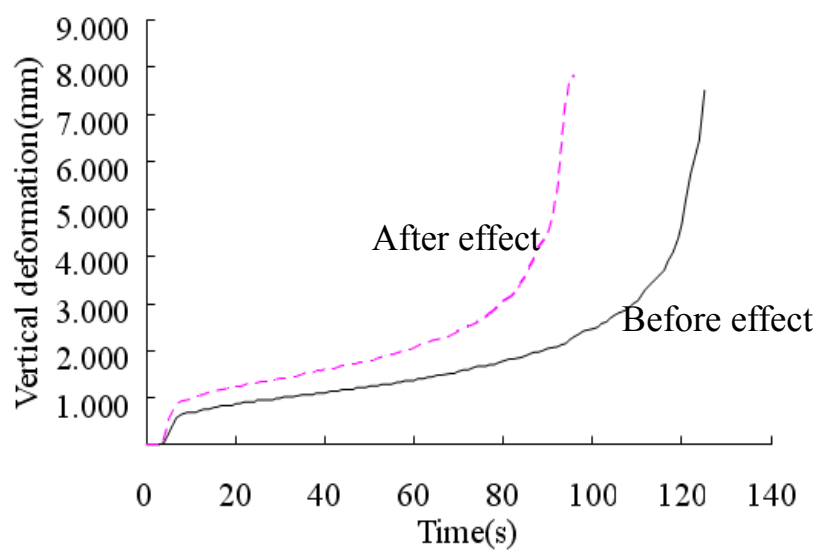

Fig. 4. Creep curve of $\mathrm{C}$ mixture

It can be seen that after the effect of dynamic water, the high temperature stability of asphalt mixtures with different grades have been reduced. The change rate of $\mathrm{A}$ is the most which the asphalt viscosity is high, and the change rate of $\mathrm{B}$ is the smallest which the asphalt viscosity is small. The order of arrangement according to the degree of reduction is $\mathrm{A}>\mathrm{B}>\mathrm{C}$. This is because asphalt 
of high viscosity contributes to the high temperature stability relatively more than the small viscosity, and when the asphalt adhesive is damage, its ability to resist deformation becomes weaker.

Gradation It is said on abroad research that $60 \%$ of the high temperature stability of asphalt depends on the skeleton effect of the aggregate gradation; asphalt binder can only have $40 \%$ contribution. In this part, B, D and E asphalt mixtures are selected to test which have different gradations, the same asphalt grade and same air voids. The experimental results are shown in Fig.5-Fig.7. The real line in the diagram is representation for the creep curve of the specimens before dynamic water effect, and the broken line is representation for the creep curve of the specimens after dynamic water effect.

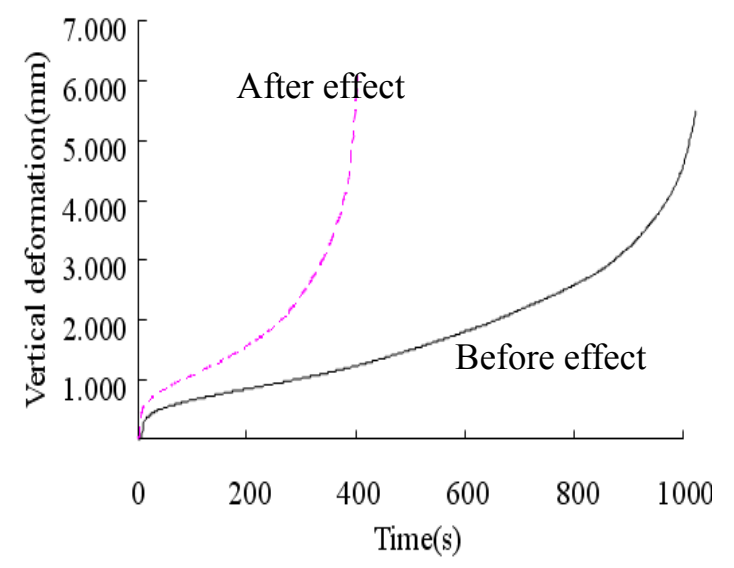

Fig. 5. Creep curve of B mixture

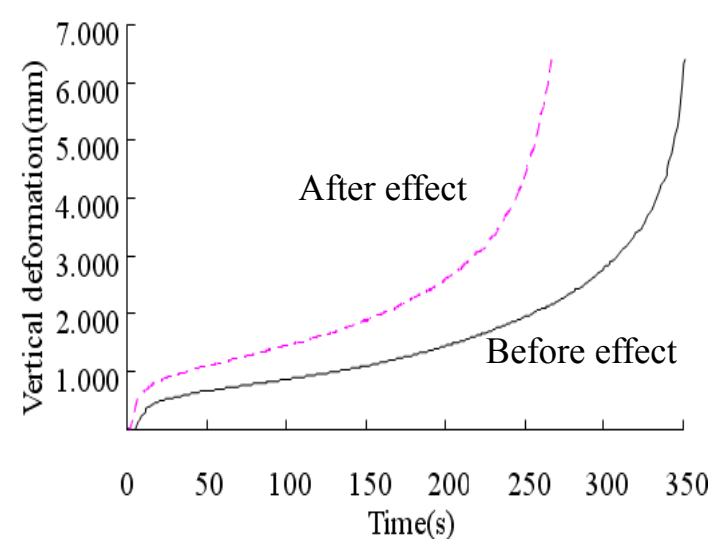

Fig. 6. Creep curve of D mixture

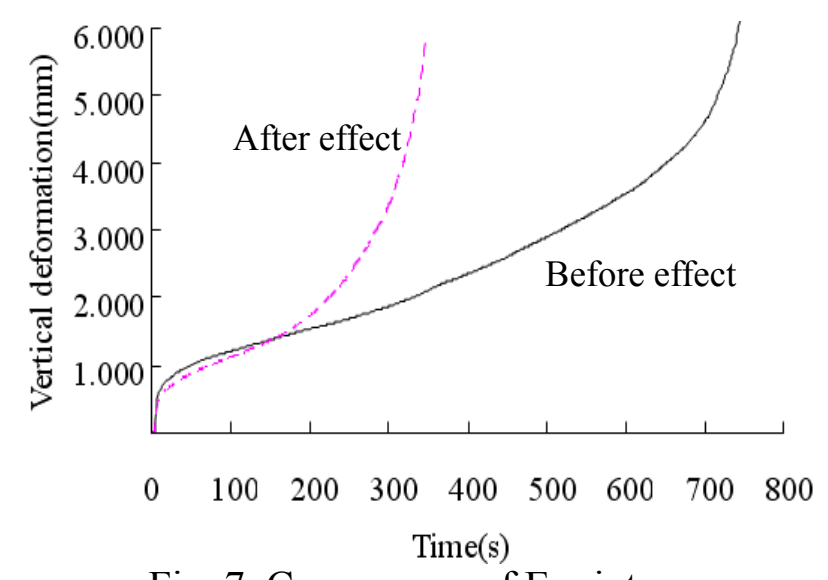

Fig. 7. Creep curve of E mixture

By the test results, the high temperature stability of asphalt mixture with different gradations which effected by dynamic water are all discount more or less. At the same $10 \%$ air voids, the high temperature stability of the dense structure of the AC-16 gradation mixture had reduced most; the skeleton structure of SMA mixture was affected by water relatively small. The order of arrangement of the three gradation according to dynamic water effect degree is AC-16>SAC-16> SMA-16. This is because after the adhesive effect attenuation between the asphalt and aggregate, the embedded squeeze support among aggregates plays a major role on high temperature deformation resistance of mixture, which is the SMA advantage. 


\section{Conclusion}

This paper introduces the effect of dynamic water into the test, develops a laboratory test machine for simulating asphalt pavement effected by dynamic water, and puts forward a test method of dynamic water effect working together with load, water and temperature. Based on this method, the specimens should be pretreatment with the dynamic water effect, and then tests the changes for the high temperature stability of asphalt mixture. This paper focused on the effect of asphalt grade and gradation type on the high temperature stability of seven kinds of asphalt mixture. The results show that the effect of dynamic water can take adverse effect for the high temperature stability of asphalt mixture. The effect degree is different under different factors. Based on the reason for the mixture resisted the dynamic water effect, it is the most unfavorable that the void ratio of the mixture is near $10 \%$, the asphalt mixture gradation of the skeleton structure is better than the suspended structure, the mixture made of the strong viscosity asphalt is more effected by water when the temperature is higher.

\section{REFERENCES}

[1] Sha Qing-lin. "Premature Damage and Its Preservative Measures of Bituminous Pavement on Expressway." China Communications Press,2011, 23-25.

[2] Plancher, Hetal. "Moisture-Induced Damage in Bituminous Pavement." International Symposium on Progrossi Nella Technologia Dei Bitumi, San Donato Milanese, Italy,1982.

[3] Theresa M Williams. "Use of environmental SEM to study asphalt-water interactions." Journal of Materials in Civil Engineering, 1998,10(2), 121-124.

[4] Saleh A1.Swailmi, Ronald L.Terrel. "Evaluation of Water Damage of Asphalt Concrete Mixtures Using the Environmental Conditioning System." Association of Asphalt Paving Technologists, 1998.

[5] Zhao Jia-jun, Huang Zhi-fu. "Disease Dispose of Highway Asphalt Pavement." East China Highway, 2000,125, 34-36.

[6] Kennedy, T.W., Roberts, F.L., and Lee, K.W.. "Evaluation of Moisture Effects on Asphalt Concrete Mixtures." Presented at the meeting of the Transportation Research Board,1983. 